\title{
Effects of the aging state and tensile strength on the fatigue properties of 6 A01 aluminum alloy
}

\author{
BaiShan Gong ${ }^{1}$, ZhenJun Zhang ${ }^{1}$, QiQiang Duan ${ }^{1}$, Zhan $\mathrm{Qu}^{1}$, Peng Zhang ${ }^{1}$, and Zhefeng \\ Zhang $^{1}$
}

${ }^{1}$ Institute of Metal Research Chinese Academy of Sciences

May 20, 2021

\begin{abstract}
Abstract To study the effects of the aging state and tensile strength on the fatigue properties of $6 \mathrm{~A} 01 \mathrm{Al}$ alloy, the high-cycle fatigue $(\mathrm{HCF})$ experiments were carried out for different aging states. The results show that the 6A01 Al alloy with the highest tensile strength at peak-aging state can exhibit the highest fatigue strength in comparison with the overaged state and the underaged state. The main reason is that the increased strength of the $6 \mathrm{~A} 01 \mathrm{Al}$ alloy at peak-aging state can improve the plastic deformation resistance and inhibit the fatigue crack initiation. Besides, the intermittent distribution of grain boundary precipitates at the peak-aging state is beneficial for reducing the fatigue damage. From these results, it is verified that the tensile strength plays a key role in the fatigue strength relative to the aging state for the low-strength $\mathrm{Al}$ alloys.
\end{abstract}

Effects of the aging state and tensile strength on the fatigue properties of 6A01 aluminum alloy

B.S. Gong ${ }^{a, b}$, Z.J. Zhang ${ }^{a, b^{*}}$, Q. Q. Duan ${ }^{a, b}$, Z. Qu ${ }^{a, b}$, P. Zhang ${ }^{a, b}$, Z.F. Zhang ${ }^{a, b^{*}}$

${ }^{a}$ Shi-changxu Innovation Center for Advanced Materials, Institute of Metal Research, Chinese Academy of Sciences, Shenyang, 110016, China

${ }^{\mathrm{b}}$ School of Materials Science and Engineering, University of Science and Technology of China. Hefei 230026, China

\begin{abstract}
To study the effects of the aging state and tensile strength on the fatigue properties of $6 \mathrm{~A} 01 \mathrm{Al}$ alloy, the high-cycle fatigue (HCF) experiments were carried out for different aging states. The results show that the $6 \mathrm{~A} 01 \mathrm{Al}$ alloy with the highest tensile strength at peak-aging state can exhibit the highest fatigue strength in comparison with the overaged state and the underaged state. The main reason is that the increased strength of the $6 \mathrm{~A} 01 \mathrm{Al}$ alloy at peak-aging state can improve the plastic deformation resistance and inhibit the fatigue crack initiation. Besides, the intermittent distribution of grain boundary precipitates at the peak-aging state is beneficial for reducing the fatigue damage. From these results, it is verified that the tensile strength plays a key role in the fatigue strength relative to the aging state for the low-strength $\mathrm{Al}$ alloys.
\end{abstract}

Keywords:6A01 Al alloy; Aging state; Tensile strength; Fatigue strength

*Corresponding authors:

Z. J. Zhang, Email:zjzhang@imr.ac.cn,Z.F. Zhang, Email:zhfzhang@imr.ac.cn 


\section{Introduction}

Low weight and high strength are the main basis for the selection of materials for high-speed trains. 6XXX series Al alloys have been widely used in the body structural parts due to their low density, medium strength, good-forming ability and excellent welding performance [1-4]. However, fatigue cracks usually happen in the $\mathrm{Al}$ alloy components because of the alternating load during long-term service [5-10]. It is estimated that $80 \% \sim 90 \%$ failures of engineering components may result from fatigue fracture [6,9], therefore, it is necessary to optimize the fatigue performance of the $6 \mathrm{XXX}$ series Al alloy to improve their fatigue damage resistance.

The fatigue performance of $\mathrm{Al}$ alloys is generally affected by two kinds of factors: i.e external factors such as service environment [11-14] and loading mode [12,15-17], and intrinsic factors including grain size, inclusion size and microstructure homogeneity [17-20]. These internal defects often lead to the initiation of fatigue cracks and control their high-cycle fatigue (HCF) properties [21]. However, no matter what kind of defects, the initiation of fatigue cracks is always caused by the localization of plastic deformation under cyclic stress lower than the nominal yield strength of the alloy. Therefore, how to inhibit strain localization during cyclic loading is the key factor to improve the fatigue performance.

For heat-treatable strengthening $\mathrm{Al}$ alloys, it is also found the aging state affects the fatigue property through influencing the strain localization. Zhang et al. [22] found that at the underaged (UA) state the fatigue life is higher than that of peak-aging (PA) for the high-strength Al alloys. The reason is that during fatigue loading, plastic deformation becomes localized in the soft precipitate-free zone (PFZ) of the PA state, which provides conditions for the initiation of fatigue cracks. Besides, Li et al . [23] found that at the UA state the fatigue life is twice that of the overaged (OA) state at the same stress amplitude for $2 \mathrm{E} 12 \mathrm{Al}$ alloy, which was also attributed to the high slip reversibility of dislocations and strain uniformity at the UA state. However, Leng et al . [24] found that the OA state of $7075 \mathrm{Al}$ alloy with higher yield strength and elongation can exhibit higher fatigue strength relative to the UA state. They attributed the reason to the high fatigue cracking resistance of the UA state because of the high strength.

From the research results above, it is still puzzled that there is not clear rule for the effect of aging state on the fatigue properties of $\mathrm{Al}$ alloys. Apart from the effect of the aging state, the tensile strength itself may also have a great effect on the fatigue strength. This is because normally, increasing the tensile strength can improve the fatigue cracking resistance [25,26], therefore, both the aging state and tensile strength should have significant effects on the fatigue properties of $\mathrm{Al}$ alloys.

For further evaluating the coupling effect of tensile strength and aging state on the fatigue properties, in this study, we employed the low-strength 6A01 Al alloy with three aging states (UA, PA and OA). Then the $\mathrm{HCF}$ tests were carried out on the 6A01 Al alloy with different tensile strengths. Finally, the influencing mechanisms of the tensile strength and aging state on the fatigue properties were deeply analyzed by investigating the microstructure evolutions at different aging states.

\section{Experimental procedures}

In this study, the industrial $6 \mathrm{~A} 01 \mathrm{Al}$ alloy was selected as a rolling plate. The chemical composition of the $6 \mathrm{~A} 01 \mathrm{Al}$ alloy was 0.48 pct. Si, 0.59 pct. $\mathrm{Mg}, 0.14$ pct. Fe, 0.14 pct. $\mathrm{Cr}, 0.05$ pct. Cu, 0.05 pct. Zn and balanced Al. To revel the influence of the aging states on the fatigue properties, we carried out heat treatment experiments. The specific heat treatment process is shown in Fig.1.

Hardness tests were administrated by a Vickers hardness tester employing a loading force of five hundred gf and a habitation time of $10 \mathrm{~s}$. Seven indentations were tested for every specimen, and therefore the norm of the center 5 indentations was adopted. The size of tensile and fatigue specimens of $6 \mathrm{~A} 01 \mathrm{Al}$ alloy are shown in Fig. 2 and Fig. 3. Tensile tests were performed on an Instron 5982 universal mechanical testing machine with a strain rate of $10^{-3} \mathrm{~s}^{-1}$ at room temperature $(\mathrm{RT})$. The tension- tension HCF tests were carried out on a GPS20 testing machine with a frequency of $100 \mathrm{~Hz}$ and load ratio $\mathrm{R}=0$ controlled by the stress amplitude.

The grain size of the $6 \mathrm{~A} 01 \mathrm{Al}$ alloy was observed by optical microscope (OM). Besides, the fatigue fracture and precipitated phase of $6 \mathrm{~A} 01 \mathrm{Al}$ alloy were observed by scanning electron microscope (SEM) and transmission 
electron microscope (TEM), respectively.

OM observations were conducted on a BX53M instrumentation, automatically ground and polished, and treated with an anodic membrane in the solution $\left(1.1 \mathrm{~g} \mathrm{H}_{3} \mathrm{BO}_{3}+3 \mathrm{ml} \mathrm{HF}+97 \mathrm{ml} \mathrm{H}_{2} \mathrm{O}\right)$ for $75 \mathrm{~s}$ at an applied voltage of $25 \mathrm{~V}$. The sample observed by TEM were punched into $3 \mathrm{~mm}$ diameter disks from slices, and then mechanically thinned to a thickness of $50 \mu \mathrm{m}$. Then TEM samples were prepared by Struers-Tenupol- 5 twinjet electro polishing device. with polishing solution of $10 \% \mathrm{HClO}_{4}$ and $90 \% \mathrm{C}_{2} \mathrm{H}_{5} \mathrm{OH}$, operated at -25 ${ }^{\circ} \mathrm{C}$ and $35 \mathrm{~V}$. TEM examinations were performed an FEI Tecnai F20 transmission electron microscope with a working voltage of $200 \mathrm{kV}$.

\section{Experimental results}

\section{Hardness variation}

To quickly determine the proper aging states, we systematically studied the hardness variation with aging time of the $6 \mathrm{~A} 01 \mathrm{Al}$ alloys at $175{ }^{\circ} \mathrm{C}$, and the result is shown in Fig. 4 . It can be seen that the highest hardness appears at an aging time of $8 \mathrm{~h}$. Besides, the hardness values are nearly the same when the aging times are $1 \mathrm{~h}$ and $72 \mathrm{~h}$, which are much lower than that of $8 \mathrm{~h}$. Therefore, we choose the aging times of $1 \mathrm{~h}$, $8 \mathrm{~h}$ and $72 \mathrm{~h}$ as the UA, PA and OA states for $6 \mathrm{~A} 01 \mathrm{Al}$ alloys, respectively, as marked in Fig. 4.

On the other hand, it could be seen that the hardness values the aged $6 \mathrm{~A} 01 \mathrm{Al}$ alloy show two peaks and a valley in between, which can be owing to the microstructure evolution with the aging time. It is generally explained that the occurrence of the first peak may be attributed to the high density of the GP zones. With the increase of aging time, the GP zones gradually transform into the $\beta$ " phase, and the second peak starts to appear due to the accumulation of the $\beta$ " phase. Therefore, the valley of the hardness value should result from the transition of the two strengthening mechanisms.

\section{Microstructures and precipitates}

The microstructures of the $6 \mathrm{~A} 01 \mathrm{Al}$ alloy at different aging states are shown in Fig. 5. It is seen that the grains are elongated along the rolling direction for the three aging states, which is a typical microstructure of $\mathrm{Al}$ alloys formed by hot extrusion [27, 28]. Besides, with the increase of aging time, the grain size remains unchanged. Although the aging treatment does not affect the grain size, it still has a great influence on the size and volume fraction of the precipitated phases, which will be elaborated in the following paragraphs.

Figs. 6(a)-3(c) shows the TEM images of the matrix precipitates for the UA, PA and OA states, severally. It is apparent that the precipitated phases are equally distributed within the matrix. Besides, with the rise of aging time, the sizes of precipitated phases step by step increase, while the density firstly increases and so decreases.

After solution aging treatment of the Al-Mg-Si alloys, it was found that the precipitation sequence of the strengthening phase during the aging process followed: SSSS - GP (I, II) zones - metastable $\beta$ "'- $\mathrm{b}\left(\mathrm{Mg}_{2} \mathrm{Si}\right)$ [29-33]. Therefore, the precipitated phases are mainly GP zones at the UA state, as shown in Fig. 6(a). The GP zones are coherent with the Al matrix. Besides, a large amount of needle-like $\beta$ " $\left(\mathrm{Mg}_{2} \mathrm{Si}\right)$ phases appeared at the PA state, as shown in Fig. 6(b). The needle-like $\beta$ " phases are semi-coherent with the Al matrix and play the main role in strengthening. The $\beta$ equilibrium phase precipitated at the OA state, as shown in Fig. 6(c). The $\beta$ phases are incoherent with the $\mathrm{Al}$ matrix. Fig. 6(d) summarizes the average size of precipitated phases at different aging states. The precipitated phases size of the UA, PA and OA states are $34 \mathrm{~nm}, 45 \mathrm{~nm}$ and $100 \mathrm{~nm}$, respectively.

\section{Tensile and fatigue properties}

Fig. 7(a) displays the tensile stress-strain curves of the $6 \mathrm{~A} 01 \mathrm{Al}$ alloy at different aging states. It is apparent that the tensile and yield strengths are the highest for the PA state, and those of the UA and OA states are very close to each other. The tensile strength of the UA, PA and OA states are $282 \mathrm{MPa}, 324 \mathrm{MPa}$ and 286 $\mathrm{MPa}$, respectively. 
The relationship between uniform elongation and tensile strength of the $6 \mathrm{~A} 01 \mathrm{Al}$ alloy is shown in Fig. 7(b). It is found that the UA state shows a better matching of strength and plasticity than that at the OA state. According to the previous studies [34-36], the materials with high strength-plasticity matching will yield a higher fatigue strength. Therefore, it is expectant that the UA state should show better fatigue properties than the OA state.

The S-N curves of the 6A01 Al alloy at different aging states are shown in Fig. 8, in which the fatigue strength was calculated by the staircase method. From Fig. 8, it is obvious that the fatigue lives of the PA state are higher than those of the UA and OA states, besides, those of UA are higher than OA. As the fatigue strength can intuitively reflect the fatigue performance, we summarized the relationship between the aging time and fatigue strength, as shown in the Fig. 8(b). It can be seen that with the increase of aging time, the fatigue strength firstly increases and then decreases, and the PA state displays the highest fatigue strength.

\section{Fatigue fractographies}

The fatigue fracture surfaces of the three states are shown in Fig. 9. It may be seen that the fatigue fracture morphologies are basically the same for the three aging states, and the fatigue cracks mainly initiated on the free surface of the specimens. Therefore, we can infer that the fatigue damage mechanism should be similar for the different aging states. For Al alloys, the fatigue sources usually originate from inclusions, porosity and heterogeneous microstructure [37-42]. However, compared with cast $\mathrm{Al}$ alloy, there are almost no inclusions and porosity in wrought aluminum alloy. It is also true through the observation of fatigue fractures. Therefore, it will be inferred that the fatigue cracking ought to be mainly caused by the heterogeneous microstructure or surface stress concentration.

\section{Discussions}

\section{Influence of tensile strength on fatigue strength}

From the experimental results above, it can be concluded that the PA state displays both the highest tensile and fatigue strength. Besides, the UA state with lower tensile strength but higher uniform elongation relative to the OA state shows higher fatigue strength. These results indicate that both the strength and elongation have important effects on the fatigue properties, as claimed by the previous studies $[35,43]$. In view that the tensile strength under the true stress-strain coordinate (named as the true tensile strength) can reflect the tensile strength and uniform elongation simultaneously, we summarize the relationship between the fatigue strength and the true tensile strength, as shown in Fig. 10(a). It is apparent that increasing the true tensile strength can effectively improve the fatigue strength. The main reason is that the true tensile strength is a comprehensive reflection of both the yield strength and the work-hardening capacity, both of which affect the fatigue damage significantly. In general, the yield strength affects the plastic deformation resistance, while the work-hardening capacity influences the strain homogeneity during cyclic deformation $[44,45]$.

Fig. 10(b) shows the work-hardening curves and the true stress-strain curves of $6 \mathrm{~A} 01 \mathrm{Al}$ alloy at the three aging states, which indicates that the UA state has higher strain-hardening ability that the OA state. Therefore, it is consistent with the fact that the UA state exhibits higher fatigue properties than the OA state. These experimental results also clarify the fact that the effect of tensile strength on the fatigue strength is greater than that of aging states for the low-strength $\mathrm{Al}$ alloys.

Besides, it can be found that the tensile strength of the $6 \mathrm{~A} 01 \mathrm{Al}$ alloy at the UA state is similar with the OA state, but the fatigue strength at the UA is higher than that at the OA state. The reason may be explained that the elongation at the UA state is higher than that at the OA state, so the slip distance of dislocations is increased, inducing the reduced plastic deformation inhomogeneity and the inhibited fatigue crack initiation.

According to the study of Pang et al. , the relationship between the fatigue strength and tensile strength of AISI 4340 high-strength steel displays a parabolic form on the whole [46]. However, our results between fatigue strength and tensile strength still show a monotonous relationship. In comparison with the highstrength steel, titanium alloy and hard $\mathrm{Al}$ alloy, the present $6 \mathrm{~A} 01 \mathrm{Al}$ alloy belongs to the low-strength 
material. Although the tensile strength of the $6 \mathrm{~A} 01 \mathrm{Al}$ alloy at the PA state is the highest among the three aging states, the tensile strength may have not yet reached the peak of the parabola. In other words, the tensile strength and fatigue strength are still in the positive correlation stage. Therefore, the fatigue strength of the $6 \mathrm{~A} 01 \mathrm{Al}$ alloy can be further improved by increasing the tensile strength.

\section{Influence of grain boundary precipitates on the fatigue properties}

For materials with low strength and high plasticity, grain boundary (GB) is that the most common initiation site for fatigue cracks [47]. Previous studies on the HCF properties of wrought alloys also indicate that the localization of plastic deformation around GB is the main reason for fatigue crack initiation $[22,48]$. Therefore, we investigated the microstructures of the GBs for various aging states. Fig. 11 shows the GB precipitates (GBP) and the PFZ at different aging states. It is quite clear from Figs. 10(a)-10(c) that the spacing of GBP and the width of PFZ firstly increase and then decrease with the increase of aging time, and they are the largest at the PA state. According to our previous study [48], increasing the space of the GBP ought to facilitate the penetration of dislocations across GBs. Besides, increasing the dimension of PFZ also benefits for the evacuation of dislocations from GBs, which also relieves the pilling-up of dislocations on GBs. Both of the on top of factors might decrease the fatigue damage along GB and improve the fatigue properties finally.

On the other hand, the dense chain-like GBP in the UA and OA states may reduce the binding energy of GBs, so that the pilling-up of dislocations is easy to prompt cracks at the GBs. However, the GBP with intermittent distribution in the PA state has little reduction on binding energy of GBs, so that the GBs are more tolerant to the dislocation impingement. This may be also the reason why the PA state has the highest fatigue strength in the $6 \mathrm{~A} 01 \mathrm{Al}$ alloy.

\section{Conclusions}

Through studying the fatigue properties of the $6 \mathrm{~A} 01 \mathrm{Al}$ alloy at different aging states, the following conclusions can be drawn.

1. Among the three aging states, the PA state displays both the highest strength and the highest fatigue strength. This indicates that the effect of the tensile strength on the fatigue strength is greater than that at the aging state for the low-strength $\mathrm{Al}$ alloy.

2. For the $6 \mathrm{~A} 01 \mathrm{Al}$ alloy at the PA state, the discontinuous distribution of the GBP and the increased width of the PFZ also contribute to the improved fatigue property.

3. The $6 \mathrm{~A} 01$ alloy at the UA state has higher strain hardening ability, better plasticity and higher true tensile strength that the OA state.

\section{Acknowledgements}

The authors would like to thank X.G. Wang, X.H. Zhou, Z.K. Zhao, B. Wang and X.J. Guan for the sample preparation, fatigue tests, SEM, TEM observations and stimulating discussions. This work was financially supported by the Youth Innovation Promotion Association CAS (Grant No. 2021192), the National Natural Science Foundation of China (NSFC) under grant Nos. 51790482, 51871223, the National Science and Technology Major Project (2017-VI-0003-0073), the Strategic Priority Research Program of the Chinese Academy of Sciences under Grant No. XDB22020202 and the LiaoNing Revitalization Talents Program XLYC1808027.

\section{References}

[1] Chakrabarti DJ, Laughlin DE. Phase relations and precipitation in Al-Mg-Si alloys with Cu additions. Progress in Materials Science. 2004;49:389-410.

[2] Gupta AK, Lloyd DJ, Couat SA. Precipitation hardening in Al-Mg-Si alloys with and without excess Si. Materials Science and Engineering A. 2001;316:11-17. 
[3] Tsao CS, Chen CY, Jeng US, et.al. Precipitation kinetics and transformation of metastable phases in Al-Mg-Si alloys. Acta Materialia. 2006;54:4621-4631.

[4] Esmaelli S, Wang X, Lloyd DJ, et.al. On the precipitation-hardening behavior of the Al-Mg-Si-Cu alloy AA6111. Metallurgical and Materials Transactions. 2003;34:751-763.

[5] Orowan E. Theory of the fatigue of metals. Proceedings of the Royal Society of London. 1939;171:79-106.

[6] Suresh S. Fatigue of Materials 2nd edition (Cambridge University Press, 1998).

[7] Schijve J. Fatigue of Structures and Materials 2nd edn (Springer, New York, 2009).

[8] Campbell FC. Elements of Metallurgy and Engineering Alloys. (ASM International, 2008).

[9] Lampman SR. ASM Handbook: Volume. 19 Fatigue and Fracture. (ASM International, 1996).

[10] Pan QS, Zhou HF, Lu QH, et.al. History-independent cyclic response of nanotwinned metals. Nature. 2017;551:214-217.

[11] Lipkin J, Swearengen J, Karnes C. Mechanical properties of 6061 Al-Mg-Si alloy after very rapid heating. Journal of the Mechanics and Physics of Solids. 1973;21:91-112.

[12] Srivatsan TS, Sriram S, Daniels C. Influence of temperature on cyclic stress response and fracture behavior of aluminum alloy 6061. Engineering Fracture Mechanics. 1997;56:531-550.

[13] Srivatsan TS, Yamaguchi K, Starke EA. The effect of environment and temperature on the low cycle fatigue behavior of aluminum alloy 2020. Materials Science and Engineering A. 1986;83:87-107.

[14] Abedrabbo N, Pourboghrat F, Carsley J. Forming of aluminum alloys at elevated temperatures - Part 1: Material characterization. International Journal of Plasticity. 2006.

[15] Myhr OR, Grong Ø, Fjær HG, et.al. Modelling of the microstructure and strength evolution in Al-Mg-Si alloys during multistage thermal processing. Acta Materialia. 2004;52:4997-5008.

[16] Minakawa K, Levan G, McEvily AJ. The influence of load ratio on fatigue crack growth in 7090-t6 and in9021-t4 p/m aluminum alloys. Metallurgicall and Materials Transactions A. 1986;17:1787-1795.

[17] Wang L, Sun Z, Kobayashi T, et.al. Cyclic deformation and low cycle fatigue behavior in a $6061 \mathrm{Al} / 22 \mathrm{vol} \%$ $\mathrm{SiC}$ whisker composite. Materials Transactions. 1996;37:762-768.

[18] Chan KS. Roles of microstructure in fatigue crack initiation. International Journal of Fatigue. 2010;32:1428-1447.

[19] Caton M, Jones J, Allison J. The influence of heat treatment and solidification time on the behavior of small-fatigue-cracks in a cast aluminum alloy. Materials Science and Engineering A. 2001;314: 81-85.

[20] Hall JN, Jones JW, Sachdev AK. Particle size, volume fraction and matrix strength effects on fatigue behavior and particle fracture in 2124 aluminum-SiCp composites, Materials Science and Engineering A. 1994;183:69-80.

[21] Wang QY, Berard JY, Rathery S, et.al. High-cycle fatigue crack initiation and propagation behavior of high-strength spring steel wires. Fatigue and Fracture of Engineering Materials and Structures. 1999;22:673677.

[22] Zhang Q, Zhu YM, Gao X, et.al. Training high-strength aluminum alloys to withstand fatigue, Nature Communications. 2020;11: 5198.

[23] Li H, Zheng ZQ, Wei XY. Effect of aging precipitation on fatigue fracture behavior of 2E12 aluminum alloy. The Chinese Journal of Nonferrous Metals. 2008;18:590-594.

[24] Leng L, Zhang ZJ, Duan QQ, et.al. Improving the fatigue strength of 7075 alloy through aging, Materials Science and Engineering A. 2018;738:24-30. 
[25] Shi CX, Zhong QP, Li CG. China Materials Engineering Canon Fundamentals of Materials Engineering, vol. 1, Chemical Industry Press, Beijing. 2005.

[26] Lee YL, Pan J, Hathaway RB, et.al. Fatigue Testing and Analysis (Theory and Practice), Elsevier Butter-worth Heinemann, Amsterdam, Boston, Heidelberg. 2005.

[27] Paulisch MC, Wanderka N, Haupt M, et.al. The influence of heat treatments on the microstructure and the mechanical properties in commercial 7020 alloys. Materials Science and Engineering A. 2015;626:254-262.

[28] Paulisch MC, Lentz M, Wemme H, et.al. The different dependencies of the mechanical properties and microstructures on hot extrusion and artificial aging processing in case of the alloys $\mathrm{Al} 7108$ and $\mathrm{Al} 7175$. Journal of Materials Processing Technology. 2016;233:68-78.

[29] Holmestad R, Marioara CD, Ehlers FJH, et.al. Precipitation in 6XXX aluminum alloys. Journal of Low Temperature Physics. 2010;171:519-525.

[30] Hasting HS, Froseth AG, Andersen SJ, et al. Composition of $\beta$ ” precipitates in Al-Mg-Si alloys by atom probe tomography and first principles calculations. Journal of Applied Physics. 2009;106:691.

[31] Falahati A, Povoden-Karadeniz E, Lang P, et.al. Thermo-kinetic computer simulation of differential scanning calorimetry curves of AlMgSi alloys: Dedicated to Professor Dr. H.-P. Degischer on the occasion of his 65th birthday. International Journal of Materials Research. 2010;101:1089-1096.

[32] Zhang H, Wang Y, Shang SL, et.al. Solvus boundaries of (meta) stable phases in the Al-Mg-Si system: First-principles phonon calculations and thermodynamic modeling. Calphad-Pergamon press.2010.

[33] Sunde JK, Marioara CD, Helvoort ATJ, et.al. The evolution of precipitate crystal structures in an Al-Mg-Si $(-\mathrm{Cu})$ alloy studied by a combined HAADF-STEM and SPED approach. Materials Characterization.2018;142:458-469.

[34] Tóth L, Yarema SY. Formation of the science of fatigue of metals. Part 1. 1825-1870. Materials Science. 2006;42:673-680.

[35] Liu R, Tian YZ, Zhang ZJ, et.al. Exploring the fatigue strength improvement of Cu-Al alloys. Acta Materialia. 2018;144:613-626.

[36] Wang B, Zhang P, Duan QQ, et.al. Optimizing the fatigue strength of $18 \mathrm{Ni}$ maraging steel through ageing treatment. Materials Science and Engineering A. 2017;707:674-688.

[37] Zabett A, Plumtree A. Microstructural effects on the small fatigue crack behavior of an aluminum alloy plate. Fatigue and Fracture of Engineering Materials and Structure. 1995;18:801-809.

[38] Browles CQ, Schijve J. The role of inclusions in fatigue crack initiation in an aluminum alloy. International Journal of Fatigue. 1973;9:171-179.

[39] Grosskreutz JC, Shaw GG. Critical Mechanisms in the Development of Fatigue Cracks in 2024-T4 Aluminum. Elementary Engineering Fracture Mechanics. 1968;56:620-629.

[40] Kung CY, Fine ME. Fatigue crack initiation and micro-crack growth in 2024-T4 and 2124-T4 aluminum alloys. Metallurgical Transactions. 1979;10:603-610.

[41] DeBartolo EA, Hillberry BM. Characterization of fatigue crack nucleation sites in 2040-T3 aluminum alloy, Fatigue 99; Proceedings of the Seventh International Fatigue Congress. (Beijing, China, 1999).

[42] Newman JC. Fracture mechanics parameters for small fatigue cracks, In: Small Crack Test Methods, ASTM STP 1149, edited by J. M, Larsen and J. E. Allison (American Society for Testing and Materials, Philadclphia,1992). 6-33.

[43] Zhang ZF, Liu R, Zhang ZJ, et.al. Exploration of unified model for fatigue property prediction of metallic material. Acta Metallurgica Sinica. 2018;54:1694-1704. 
[44] Zhang ZJ, An XH, Zhang P. Effects of dislocation slip mode on high-cycle fatigue behaviors of ultrafinegrained Cu-Zn alloy processed by equal-channel angular pressing. Scripta Materialia. 2013;68:389-392.

[45] Zhang ZJ, Zhang P, Zhang ZF. Cyclic softening behaviors of ultra-fine grained Cu-Zn alloys. Acta Materialia. 2016;121:331-342.

[46] Pang JC, Li SX, Wang ZG, et.al. General relation between tensile strength and fatigue strength of metallic materials. Materials Science and Engineering A. 2013;564:331-341.

[47] Zhang ZF, Wang ZG. Grain boundary effects on cyclic deformation and fatigue damage. Progress in Materials Science. 2008;53:1025-1099.

[48] Gong BS, Liu ZJ, Wang YL, et.al. Improving the fatigue strength of A7N01 aluminum alloy by adjusting Si content, Materials Science and Engineering A. 2019;742:15-22.

\section{Hosted file}

Author Contribution Statement.doc available at https://authorea.com/users/414706/articles/ 522675-effects-of-the-aging-state-and-tensile-strength-on-the-fatigue-properties-of6a01-aluminum-alloy

\section{Hosted file}

Data availability statement.docx available at https://authorea.com/users/414706/articles/ 522675-effects-of-the-aging-state-and-tensile-strength-on-the-fatigue-properties-of6a01-aluminum-alloy

\section{Hosted file}

Figure.docx available at https://authorea.com/users/414706/articles/522675-effects-of-theaging-state-and-tensile-strength-on-the-fatigue-properties-of-6a01-aluminum-alloy 